\title{
Downregulation of RAGE Inhibits Cell Proliferation and Induces Apoptosis via Regulation of PI3K/AKT Pathway in Cervical Squamous Cell Carcinoma
}

This article was published in the following Dove Press journal: OncoTargets and Therapy

\section{Ruyi Li iD \\ Yizuo Song \\ Lulu Zhou \\ Weibo Li \\ Xueqiong Zhu iD \\ Department of Obstetrics and Gynecology, The Second Affiliated Hospital of Wenzhou Medical University, Wenzhou, Zhejiang 325027, People's Republic of China}

Correspondence: Xueqiong Zhu Department of Obstetrics and Gynecology, The Second Affiliated Hospital of Wenzhou Medical University, No. 109 Xueyuan Xi Road, Wenzhou, Zhejiang 325027, People's Republic of China

Tel +8613906640759

Email zjwzzxq@163.com
Aim: The receptor for advanced glycation endproducts (RAGE) expression has been reported to be implicated with cancer development. In this study, the role of RAGE in the regulation of cervical squamous cancer cell proliferation, apoptosis and the mechanism of RAGE involved in the biological behaviors were explored.

Methods: The RAGE expression was overexpressed or downregulated by lentivirus transfection. The effect of RAGE expression on cell proliferation was explored by CCK-8, MTT, and BrdU assay, and the effect of RAGE on tumor development was confirmed by the xenograft mouse model along with the immunohistochemistry stain of proliferating cell nuclear antigen (PCNA). Apoptosis was investigated by flow cytometry and TUNEL assay. Western blotting was performed to investigate the expression of possible proteins, including Bax, Bcl-2, PI3K, p-PI3K, AKT, and p-AKT.

Results: Overexpression of RAGE promoted proliferation of cervical squamous cancer cell and increased PCNA expression. In the meantime, RAGE overexpression inhibited cell apoptosis along with a decrease of $\mathrm{Bax} / \mathrm{Bcl}-2$ ratio, and induction of $\mathrm{PI} 3 \mathrm{~K} / \mathrm{AKT}$ activation. The in vivo results showed that overexpression of RAGE enhanced tumor growth. Conversely, knockdown of RAGE exhibited opposed effects on cervical cancer cells and xenograft mouse model. Furthermore, RAGE inhibitor FPS-ZM1 effectively inhibited SiHa cell viability and PCNA expression, and increased cell apoptosis and Bax/Bcl-2 ratio. Moreover, PI3K inhibitor LY294002 effectively inhibited activation of PI3K and AKT, and further repressed RAGE overexpression-induced cell proliferation and apoptosis inhibition. Conclusion: RAGE promotes the growth ability of cervical squamous cell carcinoma by inducing PCNA expression and inhibiting cell apoptosis via inactivation of the PI3K/AKT pathway.

Keywords: RAGE, PI3K/AKT, cervical squamous cancer, proliferation, apoptosis

\section{Introduction}

Cervical cancer is a major cause of cancer-related death among women in the United States, with estimated 13,170 new cases and 4250 patients will die due to this disease in 2019. ${ }^{1}$ Accumulated evidence has supported the assumption that inflammation plays an important role in tumorigenesis. ${ }^{2,3}$ In line with this notion, persistent infection of human papillomavirus (most notably HPV16 and HPV18) in the cervix has been definitely defined as a major cause of cervical tumorigenesis, ${ }^{4}$ suggesting that inflammatory response may be tightly involved in development and progression of cervical cancer. However, the underlying mechanism of inflammation-induced cervical carcinogenesis has not been fully elucidated. 
The receptor for advanced glycation end products (RAGE) initially discovered in 1992, is a member of the immunoglobulin superfamily with multiple extracellular ligands. ${ }^{5}$ RAGE is implicated in the pathogenesis of various inflammatory disorders and is believed to activate multiple intracellular signaling mechanisms that fuel chronic inflammatory conditions leading to malignant transformation. ${ }^{6-9}$ The pivotal role of RAGE in pathophysiological processes suggests that this receptor is an attractive target for therapeutic interventions. Indeed, recent studies provide evidence that RAGE is up-regulated in many malignant tumors including breast, lung, pancreatic, prostate, colorectal, gastric, and liver cancers. ${ }^{10-14}$ The elevated level of RAGE protein has also been detected in a set of cancers, which is associated with increased tumor histological grade and poorer outcomes. ${ }^{12,15-18}$ Biochemically, RAGE interacts with a broad spectrum of ligands and induces a number of malignant processes including increased cell proliferation, metastasis, and decreased apoptosis. ${ }^{10,11,13,14,19,20}$ Notably, our previous study reported that RAGE was upregulated in tissues from chronic cervicitis, cervical intraepithelial neoplasia (CIN), and squamous cervical cancer (SCC) by using immunohistochemical analysis. Moreover, the expression of RAGE was gradually increased as the tumor was progressed, indicating the potential oncogenic role of RAGE in cervical squamous cancer. ${ }^{21}$ In spite of these exciting discoveries, the precise role of RAGE in cervical squamous cancer proliferation and apoptosis is unclear.

Therefore, this study explored the effects of RAGE on cell viability and apoptosis in cervical squamous cancer cells. We also explored the possible mechanisms underlying RAGE involved cell proliferation and apoptosis. Moreover, we investigated the proliferation and apoptosis behavior of SiHa cells exposed to RAGE inhibitor FPS$\mathrm{ZM} 1$, which is a high-affinity but nontoxic RAGE-specific inhibitor that has been recently shown to attenuate the $A \beta$ induced inflammatory response by blocking the ligation of $\mathrm{A} \beta$ to RAGE. $^{17}$ The aim of the present study was to establish the possible role of RAGE and the related signaling pathway in cervical cancer progression to illustrate the emerging and preliminary attempts to target RAGE as a novel strategy for cancer treatment.

\section{Materials and Methods}

\section{Antibodies and Reagents}

Antibodies to PCNA, Bax, Bcl-2, Akt, p-AKT, PI3K, p-PI3K, GFP, and PI3K/AKT inhibitor LY294002 were purchased from Cell Signaling Technology (Beverly, USA). GAPDH was obtained from Shanghai Weiao. Dulbecco's Modified Eagle's Medium (DMEM), RPMI 1640 Medium, Fetal bovine serum and $0.25 \%$ Trypsin-EDTA were purchased from Gibco (Grand Island, NY, USA). SDS-PAGE loading buffer was purchased from Beijing Solarbio. Secondary antibodies and DAB Substrate Kit were purchased from Zhongshan Goldenbridge (Beijing, China). RIPA and PMSF were obtained from Beyotime Biotechnology. TUNEL Assay was from Thermoscientific (Waltham, MA, USA). ELISA kit for human RAGE was from R\&D system. Transfer Membranes (PVDF) was from Merck Millipore (Bedford, Massachusetts, USA). Cell counting kit 8 (CCK-8) kit was purchased from BestBio Science (Beijing, China). All other chemicals were obtained from commercially available.

\section{Cell Culture and Treatment}

Human cervical cancer cell lines SiHa, CaSki, C33A and MS751 were purchased from Shanghai Cell Biology Medical Research Institute, Chinese Academy of Sciences. SiHa, C33A and MS751 cells were maintained in DMEM (Invitrogen, NY, USA) and CaSki cells were cultured in RPMI-1640 (Invitrogen, NY, USA) containing 10\% fetal bovine serum (FBS), $1 \%$ penicillin and streptomycin at $37^{\circ}$ $\mathrm{C}$ in a $5 \% \mathrm{CO}_{2}$ incubator. Cells were digested by rinsing with $0.05 \%$ trypsin and then cultured for $24 \mathrm{~h}$ for further treatment.

\section{Construction of Lentivirus}

Human GFP-RAGE cDNA was subcloned into pLentiC-mGFP vector (Origene, MD, USA) and shRAGE to pLKO.1-TRC vector (Origene, MD, USA) in vitro. The pLenti-C-mGFP vector (Vector) or pLKO.1-TRC vector (NC) without GFP-RAGE cDNA or shRAGE was used as an empty vector control. And cells treated with lipofectamine 2000 were used as blank control (Control). After confirmation using gene sequencing, virus was packed using 293T cells with two packaging vectors psPAX2 and pMD2.G. Lentiviral particles were harvested and filtered to infect cervical cancer cell lines.

\section{ELISA Assay}

The quantification of RAGE in the medium of different cervical squamous cancer cells was performed with an ELISA Kit for human RAGE according to the manufacturers' protocol. In brief, $5 \times 10^{5} \mathrm{SiHa}, \mathrm{CaSki}, \mathrm{C} 33 \mathrm{~A}$ and MS751 cells were incubated for 12, 24, 36, 48, and $72 \mathrm{hrs}$. The growth medium at each time point was harvested and 
the concentration of RAGE was measured by the Multiskan GO (Thermoscientific) at $450 \mathrm{~nm}$ wavelength. The experiment was repeated three times.

\section{MTT Assay}

The viability of cervical cancer cells was determined by MTT assay. In brief, cells (3000/well) were seeded $100 \mu \mathrm{L}$ of medium/well in 96-well plates. After overnight incubation, $10 \mu \mathrm{L}$ MTT solution was added to each well and incubated at $37^{\circ} \mathrm{C}$ for another $4 \mathrm{hrs}$ in a humidified incubator, then removed the liquid and added $100 \mu \mathrm{L} /$ well DMSO, absorbance was measured at $570 \mathrm{~nm}$ using Microplate Reader. The experiment was repeated three times.

\section{Cell Counting Kit 8 (CCK-8) Assay}

CCK-8 assay was also used to determine the proliferation ability. In brief, cells were seeded into 96-well plates at a density of 3000 cells per well. After overnight incubation, the medium was replaced with various concentrations of FPS-ZM1 $(0,0.5,1,2,4,8 \mu \mathrm{mol} / \mathrm{L})$ for the next 24,48 and $72 \mathrm{hrs}$. The following day, the medium was washed using PBS; then, $10 \mu \mathrm{L}$ of the CCK- 8 reagent was added to each well and incubated at $37^{\circ} \mathrm{C}$ for $2 \mathrm{~h}$. The absorbance value was measured at $450 \mathrm{~nm}$ wavelength using a Microplate Reader. The experiment was repeated three times.

\section{BrdU Assay}

Cells were cultured under optimum growing conditions on the glass. Added BrdU at a final concentration of $30 \mu \mathrm{g} /$ $\mathrm{mL}$ and incubated for $12 \mathrm{hrs}$. Removed BrdU medium, rinsed thrice with PBS and incubated with $3 \% \mathrm{H}_{2} \mathrm{O}_{2}$ for 10 mins. Fixed the cells with $4 \%$ paraformaldehyde for 20 mins and rinsed thrice with PBS. Added $2 \mathrm{~mol} / \mathrm{L} \mathrm{HCl}$ and incubated at $37^{\circ} \mathrm{C}$ for 5 mins and rinsed thrice with PBS. Incubated cells with $0.2 \%$ Triton $\times 100$ for 20 mins in room temperature, afterward blocked in 3\% BSA for 30 mins at room temperature. Added $100 \mu \mathrm{L} /$ glass diluted $\alpha$-BrdU (Mouse $\mathrm{mAb}$ ) and stored at $4^{\circ} \mathrm{C}$ overnight. Rinsed the cells thrice with PBS and added $100 \mu \mathrm{L}$ diluted Goat antiMouse, incubated $1 \mathrm{hr}$ at room temperature. Rinsed thrice with PBS and stained with DAB, hematoxylin for a probable time, observed under a microscope with $200 \times$ magnification. The experiment was repeated three times.

\section{Flow Cytometry Analysis}

Cells were plated at $5 \times 10^{5}$ cells/dish into $60-\mathrm{mm}$ dishes. After appropriate treatment and incubation, cells were harvested, washed with cold PBS, and resuspended with binding buffer at a concentration of $1 \times 10^{6}$ cell $/ \mathrm{mL}$. Then, the cells were double-stained with annexin V-FITC/propidium iodide or PE/7-AAD according to the manufacturer's protocol (BD Pharmingen, CA, USA). The percentage of apoptotic cells were detected by flow cytometry after staining. The experiment was repeated three times.

\section{TUNEL Assay}

For cells: Culture cells were under optimum growing conditions on the glass. After incubation for $24 \mathrm{hrs}$, rinsed thrice with PBS and fixed the cells with 4\% paraformaldehyde for 30 mins and rinsed thrice with PBS. Incubated cells with $0.3 \%$ Triton $\times 100$ for 5 mins in room temperature, afterward incubated with TUNEL detection solution for $1 \mathrm{hr}$. Rinsed the cells thrice with PBS and added DAPI solution, and incubated 2 mins at room temperature. Rinsed thrice with PBS and observed under a fluorescence microscope with $200 \times$ magnification.

For tissues: The slices were dewaxed and washed by PBS thrice. Then, incubated with $0.1 \%$ Triton $\times 100$ for 5 mins. Afterward, slices were incubated with prepared TUNEL solution for $1 \mathrm{hr}$ at $37^{\circ} \mathrm{C}$ in dark. DAPI solution was used for nuclear staining at $37^{\circ} \mathrm{C}$ for 2 mins. Slices were observed using a fluorescence microscope (magnification, $\times 200$ ).

\section{Immunohistochemistry}

After fixation, samples were paraffin-embedded and sliced. The sections were microwaved for antigen retrieval and incubated with Mouse mAb PCNA primary antibody diluted at a ratio of 1 to 200 overnight at $4^{\circ} \mathrm{C}$. Then, the sections were washed with PBS, incubated with Goat antiMouse secondary antibody for $15 \mathrm{mins}$, and allowed to perform a chromogenic reaction using a DAB Substrate Kit for color development at room temperature. Then, sections were counterstained with hematoxylin. Representative images of tumor tissues were captured using a Leica microscope.

\section{Western Blotting Analysis}

Samples were homogenized and lysed in Radio Immunoprecipitation Assay buffer with a cocktail of protease inhibitors. The total protein concentrations were quantified by the bicinchoninic acid protein assay (Thermo Scientific, IL, USA). Equal amounts of total protein were resolved by sodium dodecyl sulfate PAGE, transferred to a nitrocellulose membrane under constant voltage and blocked with Tris-buffered saline with Tween (TBST) containing 5\% non-fat dried milk. Primary 
antibodies (Mouse mAb PCNA, Rabbit mAb Bax, Bcl-2, Akt, p-AKT, PI3K, p-PI3K and GFP diluted at a ratio of 1to 1000. Mouse mAb RAGE and GAPDH diluted at a ratio of 1 to 5000 and secondary antibodies were diluted in TBST and applied with a washing step between primary and secondary antibodies' incubation. Proteins were detected using the Amersham ECL Western blotting detection kit (GE Healthcare, NJ, USA).

\section{Tumor Xenograft Model}

Female BALB/c (nu/nu) mice (4-5 weeks of age; Laboratory Animal Resources, Chinese Academy of Sciences) were group-housed under a constant photoperiod of $12 \mathrm{~h}$ light and $12 \mathrm{~h}$ dark, and were provided with sterilized food and water. Ethical and legal approval was obtained prior to the commencement of the animal study. All experimental procedures using live animals were conducted in accordance with protocols approved by the Wenzhou Medical University Institutional Animal Care and Use Committee and national guidelines and regulations. On the basis of lentivirus system which can stably upregulate or downregulate RAGE in cervical cancer cell lines, xenograft tumors were established by subcutaneously injecting SiHa cells transfected with GFP-RAGE $\left(1 \times 10^{6}\right.$ cells/mouse $)$ or RAGE-KD $\left(5 \times 10^{6}\right.$ cells/mouse $)$ in a total volume of $0.1 \mathrm{~mL}$ in PBS. Tumor volumes were calculated from caliper measurements. In detail, the long and short diameters of tumor were measured and then were calculated by the standard formula of volume $=$ (Long diameter $\times$ Short diameter $\times$ Short diameter $) / 2$. Upon terminal sacrifice, the tumors were harvested, snap-frozen in liquid nitrogen, and stored at $-80^{\circ} \mathrm{C}$ until use to Western Blot for biomarkers and TUNEL for apoptosis detection.

\section{Statistical Analysis}

All the statistical analysis was performed with SPSS 17.0 statistical software (Chicago, USA). Data are expressed as mean \pm standard deviations. All experiments were performed at least in triplicate. Two-tailed Student's $t$-test was used to analyze differences between groups and Oneway ANOVA was used to analyze differences among groups (more than two groups) when the data were normally distributed. Levene test was used for homogeneity test of variance, and the LSD was performed for homogenous data, while Dunnett's T3 was performed for heterogeneous data. $P<0.05$ was considered to be statistically significant.

\section{Results}

\section{RAGE Is Both Expressed and Secreted by Human Cervical Cancer Cells}

The intracellular expression level of RAGE protein in four different cervical squamous cancer cell lines including SiHa, CaSki, C33A and MS751 was investigated. Western blotting analysis data showed that RAGE was expressed in all cervical cancer cell lines (Figure 1A). Notably, the RAGE protein level was the highest in SiHa cells whereas it is the lowest in CaSki cells (Figure 1A). Subsequently, the extracellular expression of RAGE in four cervical squamous carcinoma cells was also detected. The results of ELISA showed that the concentration of RAGE protein was significantly increased in a time-dependent manner in the supernatants of all cell lines, among which $\mathrm{SiHa}$ cells exhibited the highest extracellular RAGE expression. Consistently, the lowest concentration of RAGE protein was also observed in the supernatant of CaSki cells (Figure 1B). Collectively, these results indicated that RAGE protein was both expressed in cervical squamous cancer cells and secreted by these cells.

\section{Inhibition of RAGE Expression by FPS-ZMI Suppresses the Proliferation and Promotes the Apoptosis of $\mathrm{SiHa}$ Cells}

According to the results above, SiHa cells were selected to investigate the effect of RAGE expression on the proliferation and apoptosis of cervical squamous cancer cells. The specific RAGE inhibitor FPS-ZM1 was employed herein. Application of FPS-ZM1 dose- and timedependently reduced SiHa cells viability along with the downregulation of proliferative protein PCNA $(P<0.05$; Figure $1 \mathrm{C}$ and $\mathrm{D})$. In addition, the apoptosis of $\mathrm{SiHa}$ cells was significantly induced by $1 \mu \mathrm{M}$ FPS-ZM1 as compared with the control group $(P<0.05$; Figure $1 \mathrm{E})$. In keeping with this result, FPS-ZM1 dramatically enhanced Bax/Bcl2 ratio in a dose-dependent fashion $(P<0.05$; Figure $1 \mathrm{E}$ and F).

\section{Cervical Squamous Cell Lines with RAGE Overexpression and Knockdown are}

\section{Constructed via Lentivirus Infection}

On the basis of RAGE expression in four wild type cervical squamous cell lines, SiHa and CaSki cells were stably 
A

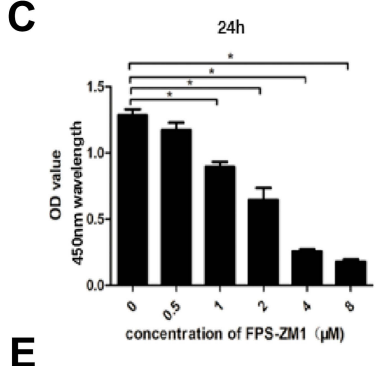

E

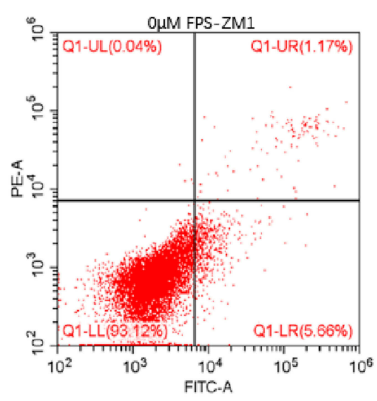
GAPDH

C
B

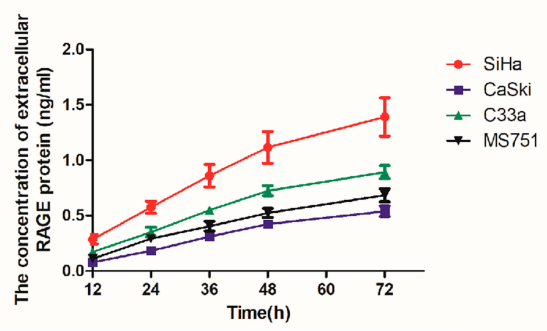

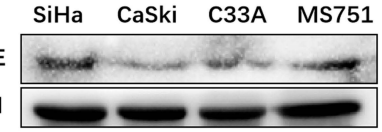
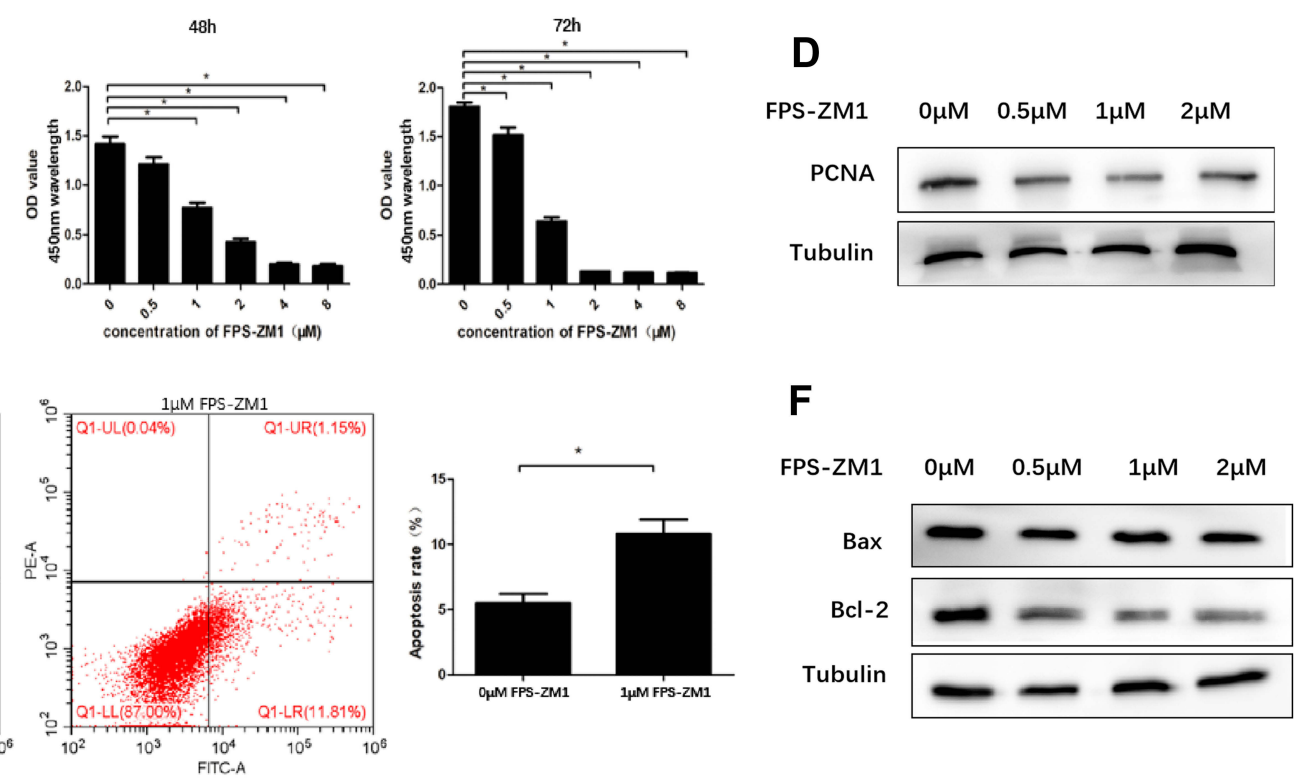

Figure I Intracellular and extracellular RAGE expression in four cervical squamous cancer cell lines SiHa, CaSki, C33A and MS75I and the effect of RAGE inhibitor FPS$\mathrm{ZMI}$ on $\mathrm{SiH}$ cell proliferation and apoptosis. (A) Intracellular RAGE expression in four squamous cancer cell lines SiHa, CaSki, C33A and MS75I was measured by Western blotting. (B) The concentration of extracellular RAGE protein in cervical squamous cancer cell lines SiHa, CaSki, C33A and MS75I was tested by ELISA. (C) The proliferation ability of SiHa cells treated with RAGE inhibitor FPS-ZMI was tested by CCK-8 assay. (D) Proliferation-related protein PCNA expression level in SiHa treated with different concentration of RAGE inhibitor FPS-ZMI was measured by Western blotting. (E) The effect of FPS-ZMI (I $\mu$ mol/L) on cell apoptosis through flow cytometry assay in $\mathrm{SiHa}$ cells. (F) Apoptosis-related protein Bax, Bcl-2 expression levels in SiHa cells treated with FPS-ZMI were measured by Western blotting. $0 \mu$ M: cells treated with DMSO and without FPS-ZMI. Values are expressed as the mean \pm SD. $* P<0.05$.

transfected with GFP-RAGE to overexpress RAGE, while SiHa cells were chosen to construct RAGE knockdown cells through RAGE-KD plasmid lentiviral infection. The GFP-green fluorescence was observed to determine the RAGE expression in both cell lines by fluorescence microscope. The protein levels of GFP-RAGE or RAGE were determined in SiHa and CaSki cells by Western blotting. Both SiHa and CaSki cells transfected with GFP-RAGE plasmid displayed strong fluorescence signal, which indicated that RAGE was overexpressed successfully in these two cell lines. When compared with empty vector groups, a significantly higher level of GFP-RAGE was found in both $\mathrm{SiHa}$ and CaSki cells transfected with GFP-RAGE $(P<0.05$; Figure $2 \mathrm{~A}$ and $\mathrm{B})$. On the contrary, SiHa cells transfected with RAGE-KD plasmid exerted a lower RAGE expression than the negative control (NC) group
$(P<0.05$; Figure 2C). Then, these cell lines were utilized in further experiments.

\section{Overexpression of RAGE Promotes SiHa and CaSki Cells Proliferation}

Next, the effect of RAGE expression on the proliferation behavior of $\mathrm{SiHa}$ and CaSki cells by MTT and BrdU assays were detected. The MTT results showed that overexpression of RAGE significantly promoted cell proliferation in both $\mathrm{SiHa}$ and CaSki cells, as compared with the vector group $(P<0.05$; Figure 3A). Similarly, BrdU results revealed thicker nuclear stain dots in the RAGE overexpression group of both $\mathrm{SiHa}$ and CaSki cells than that in the vector group $(P<0.05$; Figure $3 \mathrm{~B})$. In addition, significant upregulation of PCNA protein in both cells with RAGE overexpression further confirmed the promotive 
A

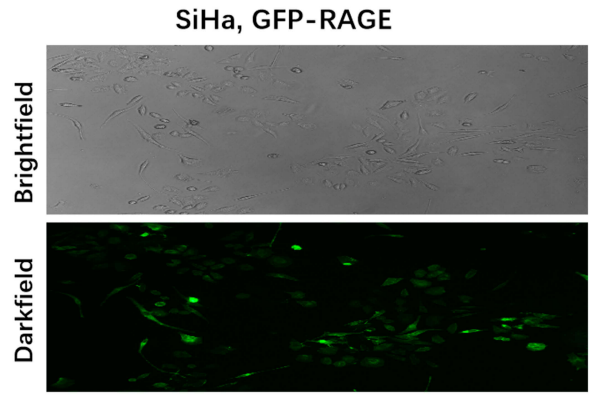

$\mathrm{SiHa}$, Vector
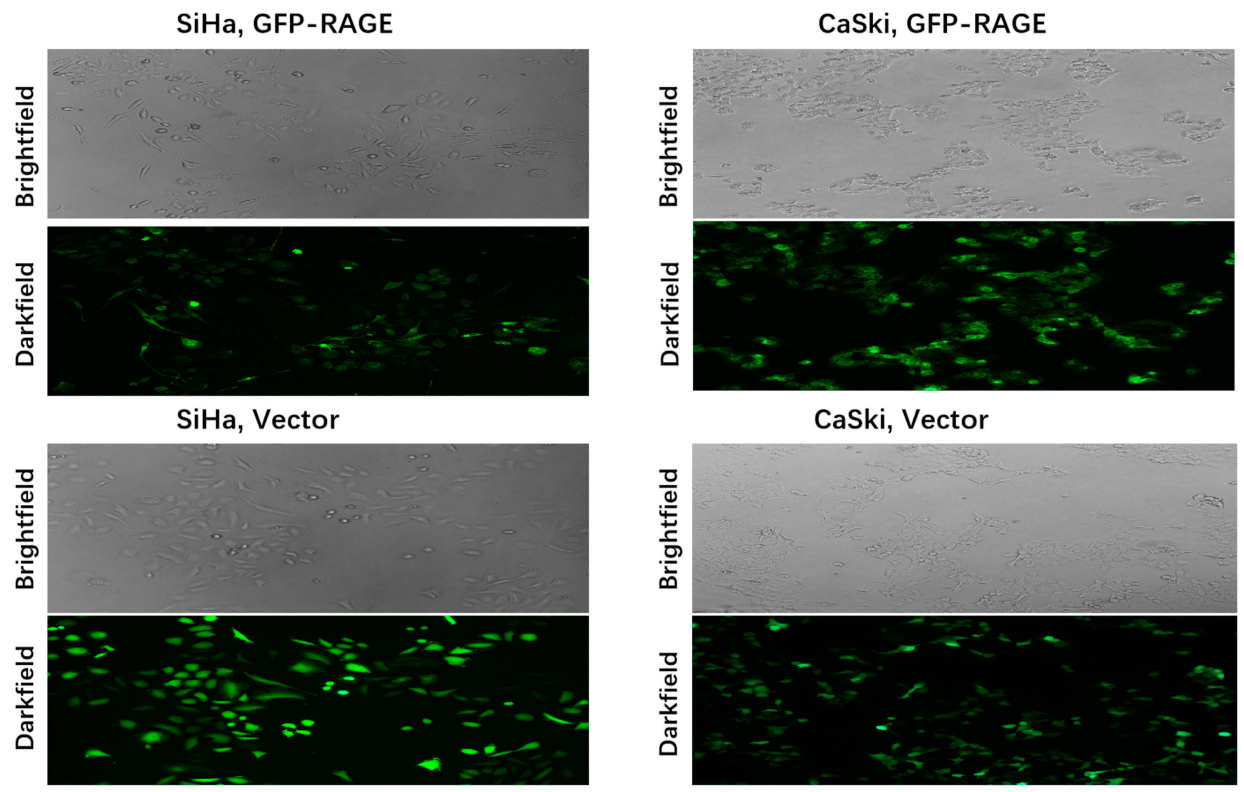

B

$\mathrm{SiHa}$

CaSki

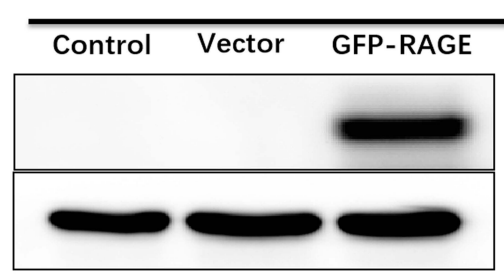

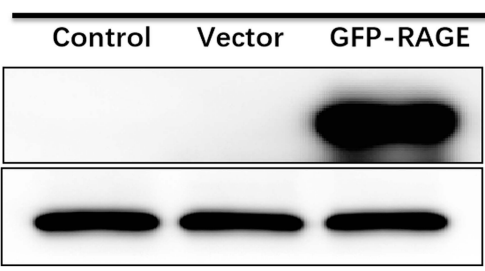

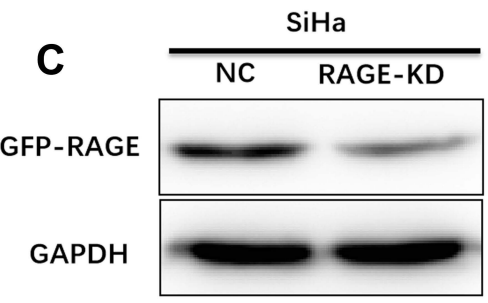

Figure 2 RAGE expression in cervical squamous cancer cell lines SiHa and CaSki stably transfected with GFP-RAGE plasmid and SiHa cells stably transfected with RAGE-KD via lentivirus. (A) SiHa and CaSki cell lines overexpressing GFP-RAGE were observed under brightfield and their GFP-green fluorescence were observed under darkfield of microscope ( $\times 100$ magnification). (B) GFP-RAGE protein expression in SiHa and CaSki cells was measured by Western blotting. (C) RAGE protein expression in SiHa cells transfected with RAGE-KD compared with control group was measured by Western blotting.

effect of RAGE in cell proliferation ( $P<0.05$; Figure $3 \mathrm{C}$ ). Conversely, shRNA mediated-RAGE knockdown in $\mathrm{SiHa}$ cells significantly inhibited cell proliferation by MTT and BrdU assays $(P<0.05$; Figure $3 \mathrm{D}$ and $\mathrm{E})$, which was further verified by the downregulation of PCNA $(P<0.05$; Figure 3F).

\section{Overexpression of RAGE Inhibits $\mathrm{SiHa}$ and CaSki Cell Apoptosis}

We further detected the effect of RAGE expression on apoptosis $\mathrm{SiHa}$ and CaSki cells in vitro, using the flow cytometry assay and TUNEL assays. As a result, RAGE overexpression decreased the apoptotic rates of both $\mathrm{SiHa}$ and CaSki cells as compared to vector groups $(P<0.05$; Figure $4 \mathrm{~A}$ and $\mathrm{B}$ ). In addition, TUNEL results showed RAGE overexpression decreased cell apoptosis in both cell lines (Figure 4C and D). Furthermore, Western blotting data revealed that RAGE overexpression induced the downregulation of Bax and activation of Bcl-2, leading to the decrease of Bax/Bcl-2 ratio ( $P<0.05$; Figure $4 \mathrm{E})$. Contrarily, shRNA mediated-RAGE knockdown increased the apoptosis percentage in SiHa cells with an increase of $\mathrm{Bax} / \mathrm{Bcl}-2$ ratio compared with the corresponding control group $(P<0.05$; Figure $4 \mathrm{~F}$ and $\mathrm{G})$.

\section{Overexpression of RAGE Promotes the Tumor Growth and Inhibits the Apoptosis of Cervical Cancer Cells in vivo}

A SiHa cells xenograft mouse model was established and used to explore the influence of RAGE on the growth and apoptosis of cervical squamous cancer. Compared with vector group, mice injected with RAGE-overexpression SiHa cells showed high proliferative activity in the tumor volume from 6 weeks onward $(P<0.05$; Figure 5A). Further immunohistology analysis also detected more abundant PCNA expressions in the xenograft tumor tissue after RAGE upregulation ( $P<0.05$; Figure 5B). In the meantime, TUNEL assay demonstrated that RAGE 
A

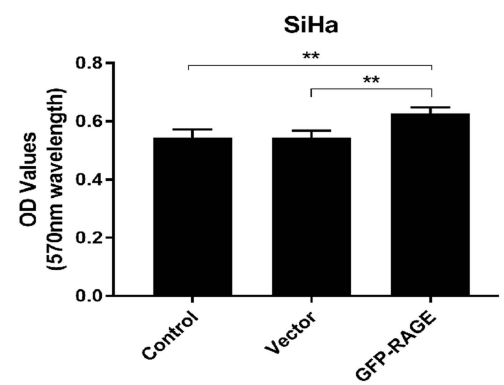

B
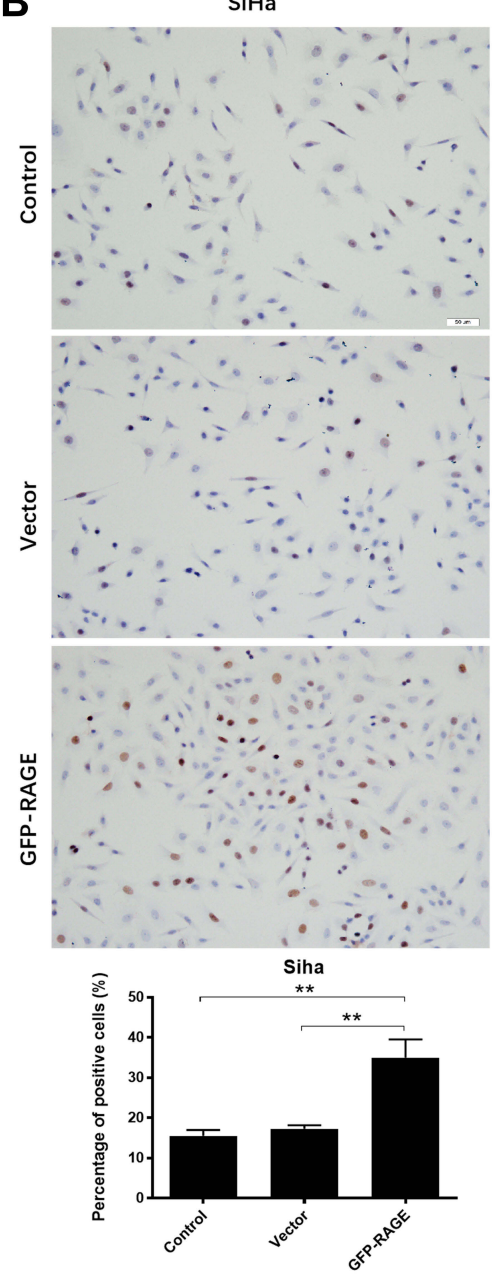

C

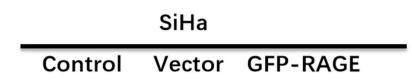

PCNA

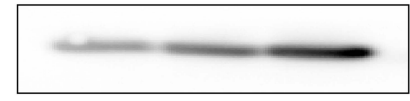

GAPDH

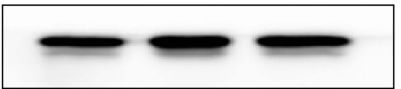

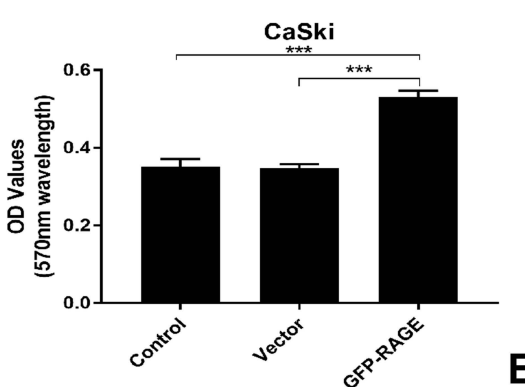

CaSki

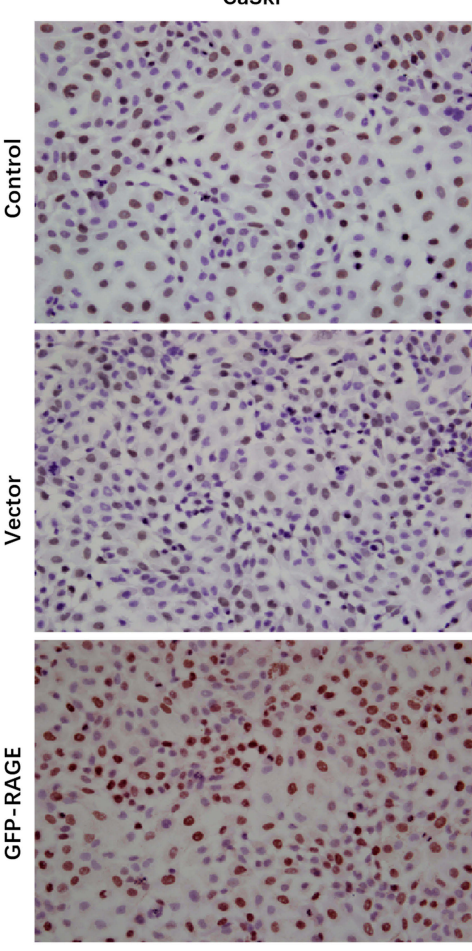

Caski

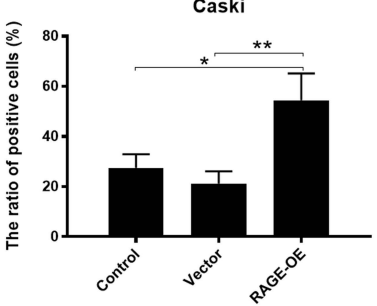

CaSki

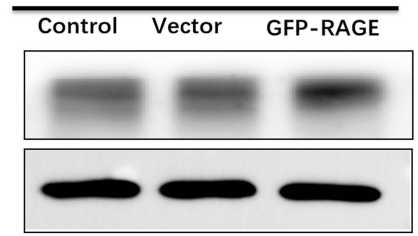

D

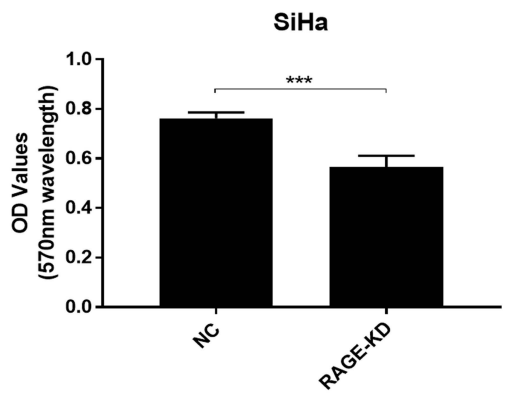

E
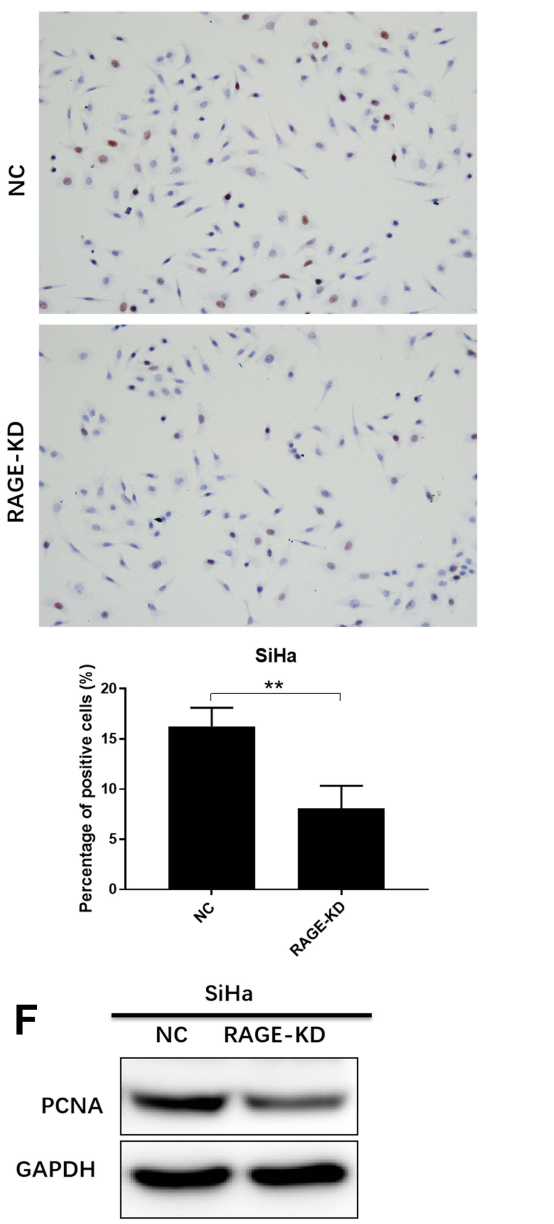

Figure 3 The effect of RAGE expression level in cervical squamous cancer cell lines SiHa and CaSki on cell proliferation. (A) The viability of cells overexpressed GFP-RAGE was analyzed by MTT. (B) BrdU test on $\mathrm{SiHa}$ and CaSki cell lines overexpressed GFP-RAGE (upper panel, $\times 200$ magnification) and the count result of positive cells stained by BrdU (lower panel). (C) Proliferation-related protein PCNA expression level in SiHa and CaSki cells overexpressed GFP-RAGE was detected by western blotting. (D) The viability of cells expressed RAGE-KD was analyzed by MTT. (E) BrdU test on SiHa cells expressed RAGE-KD (upper panel, $\times 200$ magnification) and the count result of positive cells stained by BrdU (lower panel). (F) Proliferation-related protein PCNA expression level in SiHa cells expressed RAGE-KD was detected by Western blotting. Values are expressed as the mean \pm SD. $* P<0.05$, $* * P<0.01$, $* * * P<0.001$. 


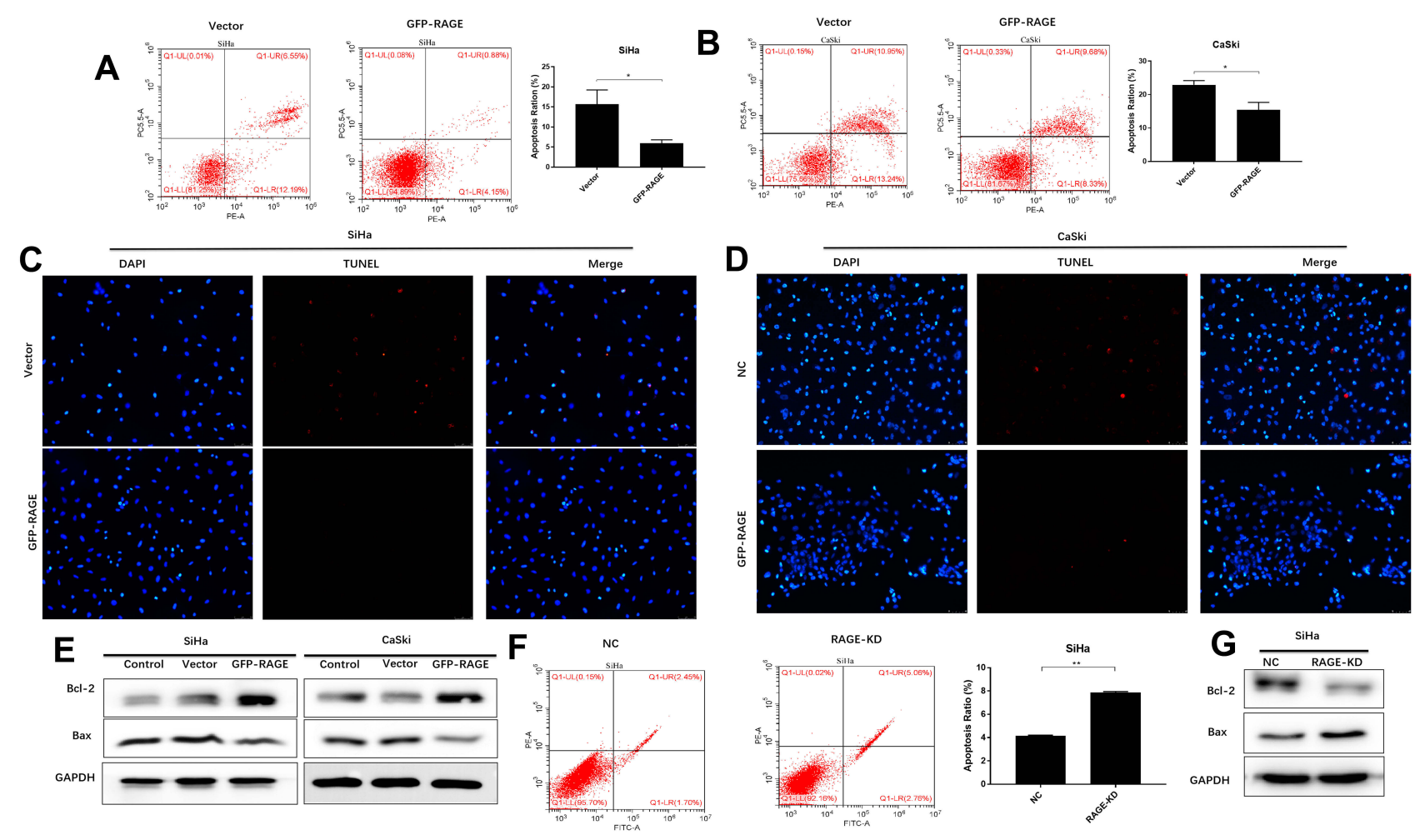

Figure 4 RAGE expression inhibits apoptosis and promotes PI3K/AKT activation. The effect of overexpression of GFP-RAGE on SiHa (A) or CaSki (B) cell apoptosis by flow cytometry assay (left and middle panel) and apoptosis ratio between vector and GFP-RAGE group (right panel). The effect of overexpression of GFP-RAGE on SiHa (C) or CaSki (D) cell apoptosis by TUNEL assay. (E) Apoptosis-related proteins Bax, Bcl-2 expression levels in SiHa and CaSki cells expressed GFP-RAGE or matched vector or control by Western blotting. (F) The effect of the downregulation of RAGE on cell apoptosis by flow cytometry assay in SiHa cells (left and middle panel) and apoptosis ratio between vector and GFP-RAGE group (right panel). (G) Apoptosis-related proteins Bax, Bcl-2 expression levels in SiHa cells expressed RAGE-KD compare with the control group by Western blotting. Values are expressed as the mean \pm SD. $* P<0.05, * * P<0.01$.

overexpression significantly inhibited the apoptosis of SiHa cell xenografts (Figure 5C).

Oppositely, the tumor volume was significantly decreased at the beginning of 4 weeks in RAGE-KD SiHa cell xenograft mice compared with the $\mathrm{NC}$ group in vivo, along with downregulation of PCNA $(P<0.05$; Figure 5D and $\mathrm{E})$. In addition, RAGE knockdown induced tumor tissue apoptosis detected by TUNEL assay (Figure 5F).

\section{PI3K/AKT Is Involved in RAGE Expression-Related Apoptosis}

To clarify the underlying pathway of RAGE in cervical squamous cancer development, the PI3K/AKT signaling pathway was analyzed. Western blotting analysis demonstrated that PI3K/AKT was activated by RAGE overexpression $(P<0.05$; Figure 6A) and suppressed after RAGE knockdown $(P<0.05$; Figure 6B) in SiHa cells, respectively. A specific inhibitor of PI3K (LY294002), which also effectively inhibits AKT phosphorylation, was added to the SiHa cells supernatant with RAGE overexpression, resulting in increased cell apoptosis $(P<0.05$; Figure 6C). Consistent with this, activation of PI3K/AKT by RAGE overexpression was reversed by LY294002 along with the downregulation of PCNA and upregulation of Bax/Bcl-2 ratio (Figure 6D). These findings showed that activation of the PI3K/AKT was essential for RAGE to inhibit cervical cancer cell apoptosis.

\section{Discussion}

RAGE is a central core of a multi-ligand signaling system that drives innate immune-inflammatory responses. ${ }^{22}$ Ligand binding to RAGE induces a sustained activation and overexpression of RAGE, which leads to prolonged inflammatory reactions and plays a causative role in human cancers. ${ }^{10,23}$ In this work, we identified that RAGE acted as an oncogenic role in cervical squamous cancer and $\mathrm{PI} 3 \mathrm{~K} / \mathrm{AKT}$ pathway was responsible for RAGE-mediated cervical squamous cancer progression.

In fact, the expression of RAGE is extremely low or even absent in healthy tissues and cells because it is not essential to life. ${ }^{24}$ Multiple clinical studies have revealed 


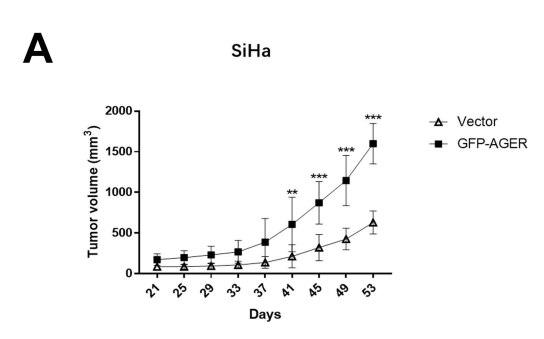

\section{C}
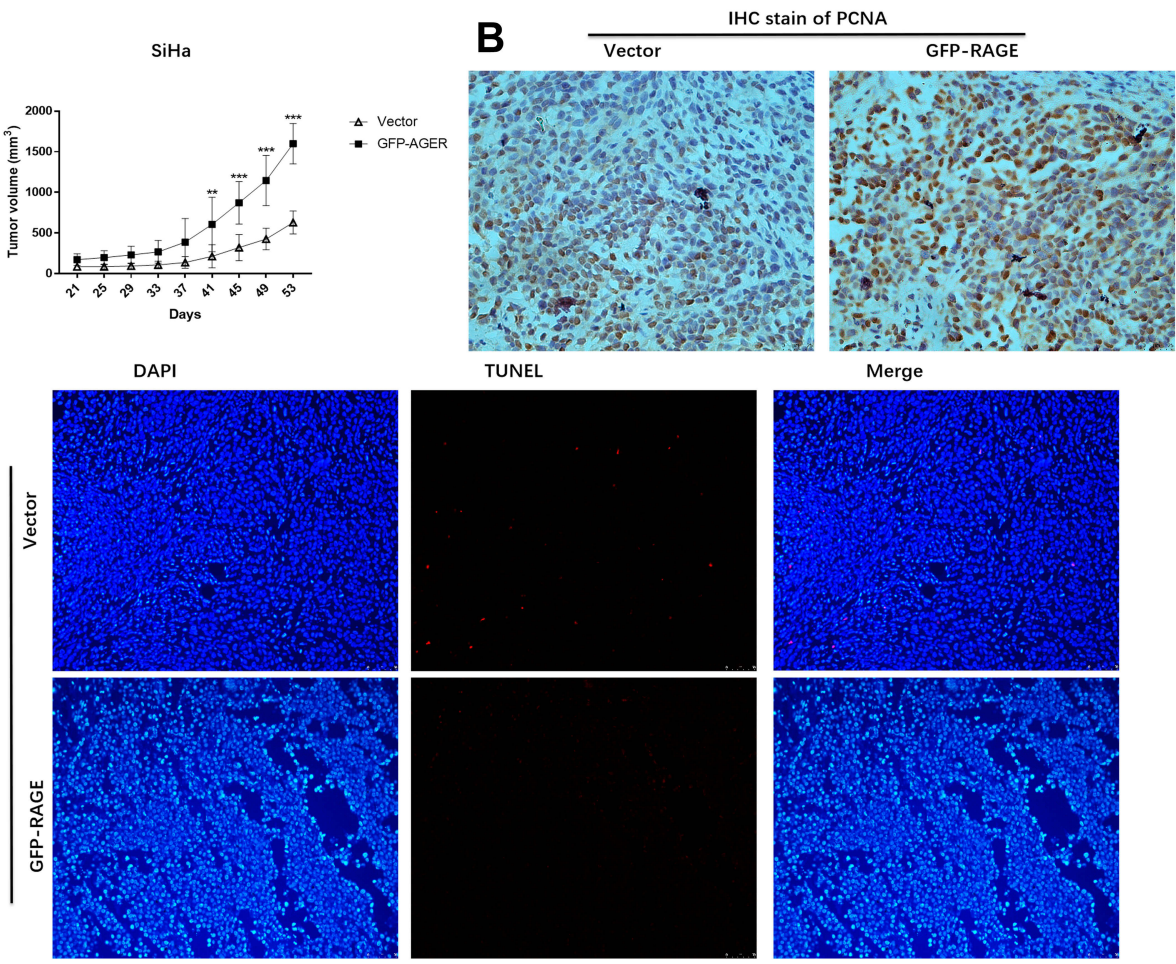

TUNEL

Merge
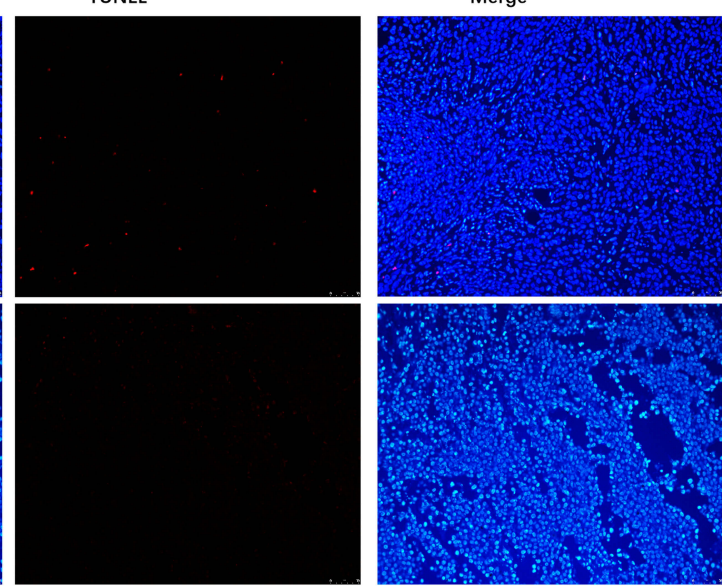

D

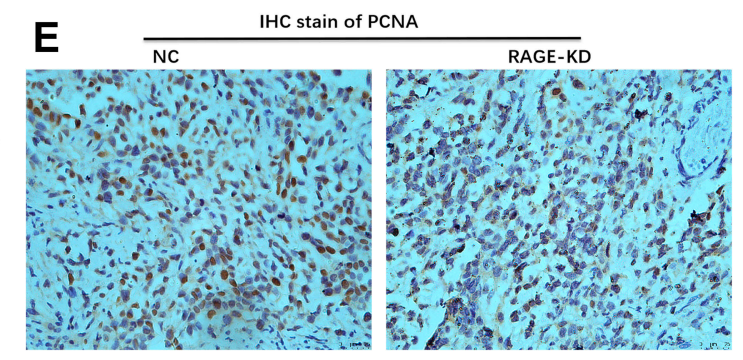

F
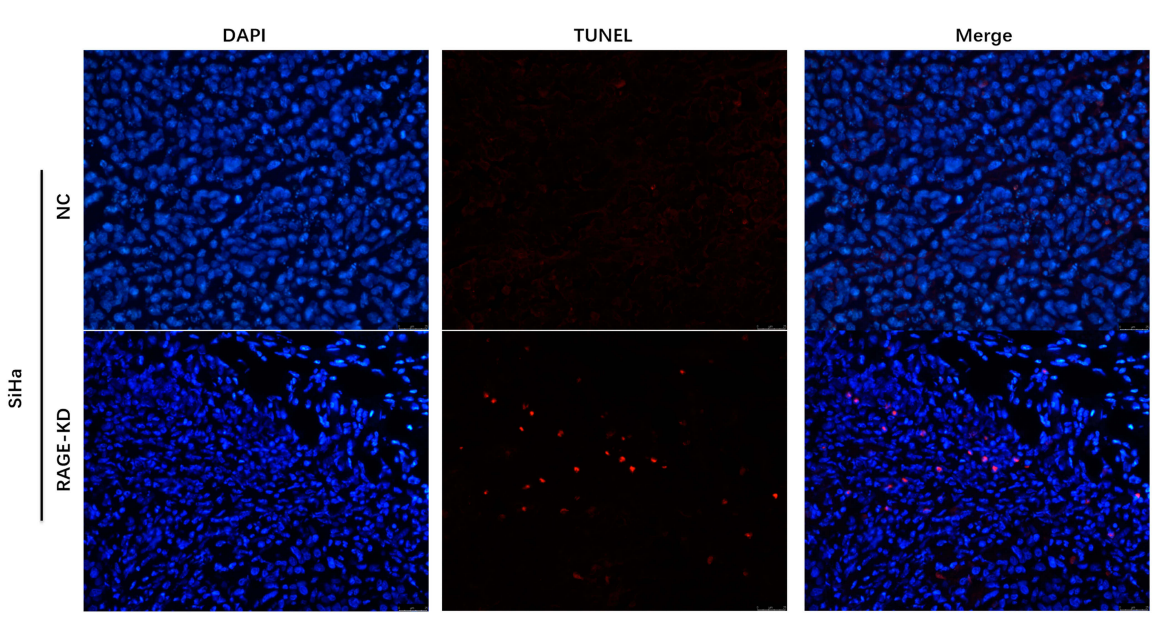

Figure 5 The effect of RAGE expression on tumor growth in vivo. (A) Tumor growth of Balb/c nude mice injected with SiHa overexpressed GFP-RAGE or Vector. (B) Protein expression levels of PCNA in tumor tissue overexpressed GFP-RAGE or Vector by IHC. (C) The effect of overexpression of RAGE on tumor tissue apoptosis by TUNEL assay. (D) Tumor growth of Balb/c nude mice injected with SiHa expressed RAGE-KD or NC. (E) Protein expression levels of PCNA in tumor tissue expressed RAGE-KD or NC by IHC. (F) The effect of RAGE knockdown on tumor tissue apoptosis by TUNEL assay. Values are expressed as the mean \pm SD. $* * P<0.0$ I, $* * * P<0.00$ I.

a strong expression of RAGE in various malignancies such as gastric, ${ }^{18}$ liver, ${ }^{25}$ pancreatic, ${ }^{26}$ colon, ${ }^{17,27}$ and prostate $^{16}$ cancers. Herein, we observed both intracellular and extracellular RAGE expressions in cervical squamous cancer cells, with the highest in $\mathrm{SiHa}$ cells and lowest in CaSki cells. Therefore, SiHa cells were selected to explore 


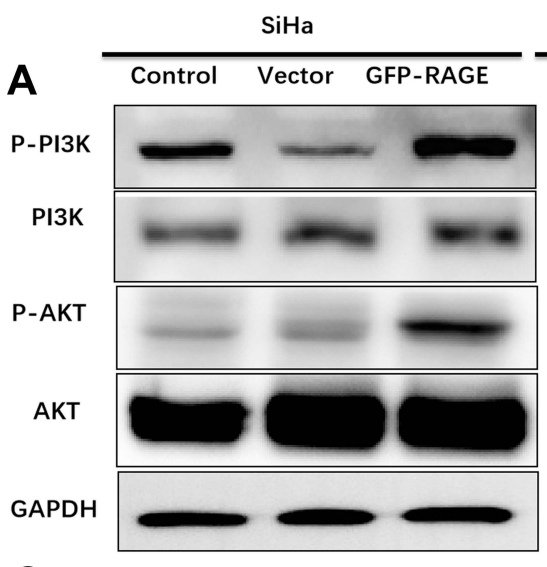

C
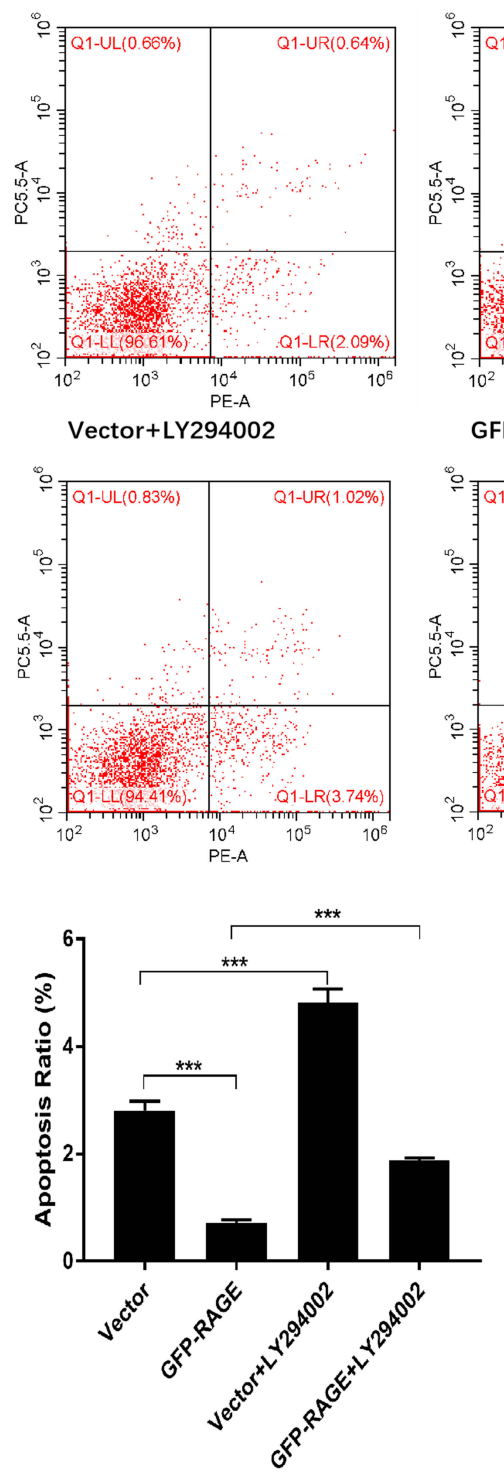

CaSki

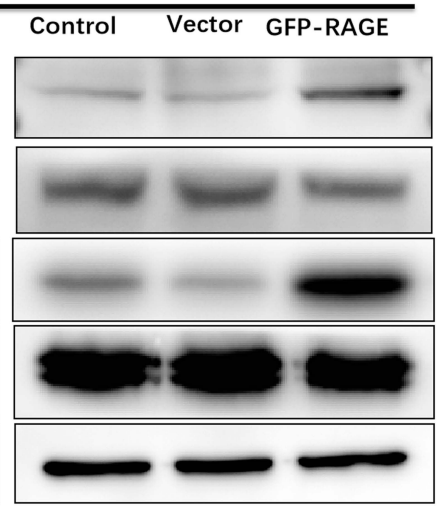

GFP-RAGE

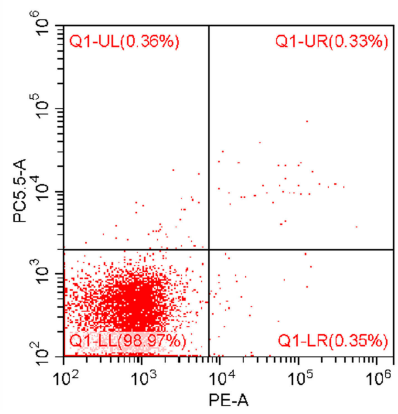

GFP-RAGE+LY294002

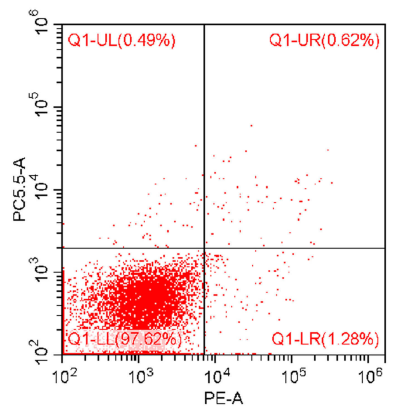

D

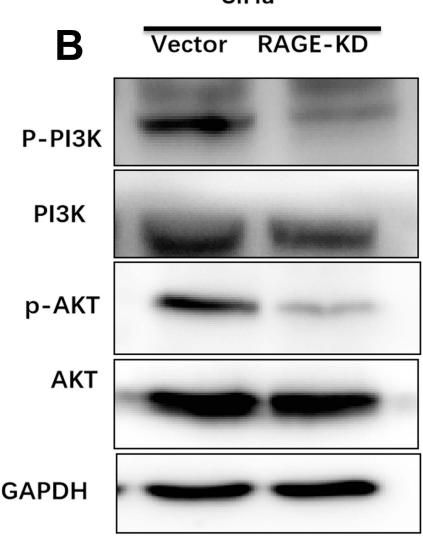

LY294002

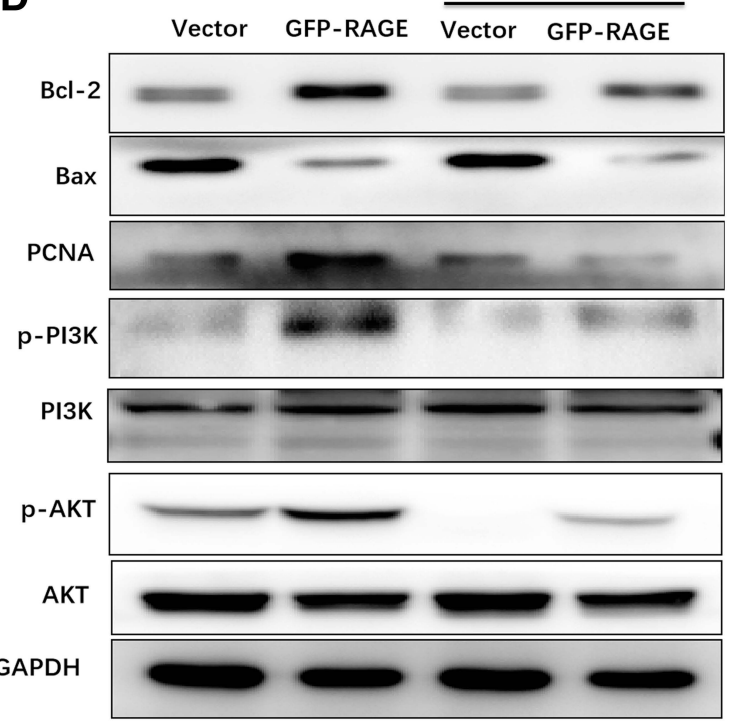

Figure 6 RAGE overexpression inhibits cell proliferation and induces apoptosis via inhibition of PI3K/AKT activation. (A) PI3K/AKT protein expression in SiHa and CaSki cells overexpressed GFP-RAGE compared with the control and vector group by Western blotting. (B) PI3K/AKT protein expression in SiHa expressed RAGE-KD compared with control group by Western blotting. (C) The effect of LY294002 on cell apoptosis by flow cytometry assay. (D) The effect of LY294002 on PI3K/AKT, Bax, Bcl-2 and PCNA expression by Western blotting. Values are expressed as the mean \pm SD. $* * * P<0.00 \mathrm{I}$.

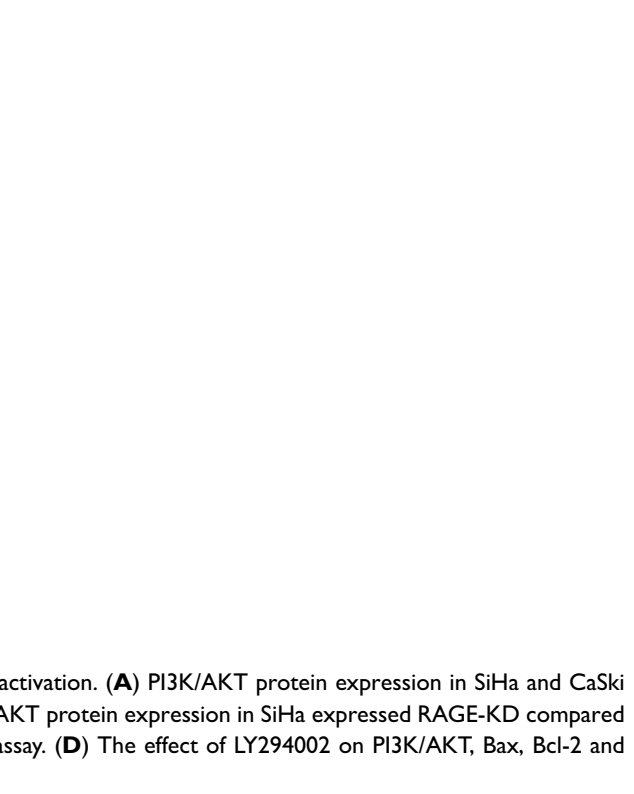


the influence of RAGE inhibition on its growth and apoptosis. Using the specific inhibitor (FPS-ZM1) of RAGE, the proliferation was significantly suppressed in a timeand dose-dependent way and the apoptosis was also induced in a dose-dependent manner in $\mathrm{SiHa}$ cells. PCNA is a nuclear protein and is essential for DNA replication and repair, whose overexpression represents the abnormal cell proliferation. ${ }^{28}$ Additionally, the Bax/ Bcl-2 ratio is a "rheostat" that regulates cell death. Under the stimulation of external factors, cell death ultimately depends on the balance between Bax and Bcl-2 expression. ${ }^{6,29}$ Moreover, these results were further confirmed by Western blotting analysis showing a decreased expression of PCNA and an increased Bax/Bcl-2 ratio. Constien et $\mathrm{al}^{30}$ have found that mice with RAGEknockout $\left(\mathrm{RAGE}^{-/-}\right)$are viable and physiologically normal, suggesting that therapeutic targeting of RAGE may be safe in humans. Indeed, several small-molecule RAGE antagonists have become available in basic researches for treating cancers. ${ }^{22,31,32}$ Hence, targeting RAGE may also become a promising therapeutic strategy for cervical squamous cancer treatment.

To further investigate the role of RAGE in the development of cervical squamous cancer, we upregulated RAGE in both SiHa and CaSki cells and knocked it down in SiHa cells by lentivirus transfection, respectively. Previous studies have shown that increased RAGE expression significantly promotes the proliferation of vascular smooth muscle cells. ${ }^{33}$ Furthermore, similar to the growth-promoting function of RAGE in colon, ${ }^{34}$ endometrial, ${ }^{22}$ pancreatic, ${ }^{35}$ and nonsmall cell lung ${ }^{36}$ cancer cells, our present results showed that RAGE overexpression significantly promoted cell proliferation and suppressed apoptosis of $\mathrm{SiHa}$ and CaSki cells, whereas knockdown of RAGE resulted in opposite biological processes in SiHa cells. Subsequently, SiHa cells xenografts with RAGE overexpression and knockdown in female nude mice were used to explore the function of RAGE in cervical squamous cancer in vivo. Results showed that mice inoculated with RAGE-overexpressing $\mathrm{SiHa}$ cells displayed a significant tumor volume from 6 weeks onward. Conversely, RAGE silencing led to a remarkably reduced the tumor volume in xenograft mice at the beginning of 4 weeks. Further, the mechanism of RAGE involved in proliferation and apoptosis were explored in our study. As shown, overexpression of RAGE significantly increased the expression level of PCNA protein and decreased the Bax/Bcl-2 ratio in both $\mathrm{SiHa}$ and CaSki cells, which were reversed in RAGE-knockdown SiHa cells. Similarly, SiHa cells xenografts with RAGE overexpression in female nude mice exhibited increased PCNA expression detected by IHC and decreased apoptosis detected by TUNEL assay. SiHa cells xenografts with RAGE knockdown resulted in decreased PCNA expression and increased apoptosis. However, the precise molecular pathway by which RAGE regulates cervical cancer cell growth and apoptosis remains still unclear.

There is mounting evidence suggesting that the PI3K/ AKT signaling pathway plays an indispensable role in the regulation of cellular features such as survival, proliferation, and apoptosis. ${ }^{37}$ The research of Tian et $\mathrm{al}^{38}$ shows the PI3K/AKT pathway is involved in lung cancer cell proliferation and apoptosis. Fang et $\mathrm{al}^{37}$ reveal that PI3K/ AKT signaling pathway plays an important role in kidney cell apoptosis. Another research demonstrates that radiation could promote cancer cell survival through activating the PI3K/AKT pathway. ${ }^{39}$ Our results showed overexpression of RAGE intensively activated PI3K/AKT in both $\mathrm{SiHa}$ and CaSki cells and knockdown of RAGE inhibited $\mathrm{PI} 3 \mathrm{~K} / \mathrm{AKT}$ phosphorylation in SiHa cells. To further analyze the role of PI3K/AKT signaling pathway on RAGEmediated proliferation and apoptosis in cervical squamous cancer cells, PI3K/AKT specific inhibitor LY294002 was applied. As seen, LY294002 effectively inhibited RAGEinduced PI3K/AKT activation. In the meantime, PI3K/ AKT inhibition downregulated PCNA protein level along with a decrease of $\mathrm{Bcl}-2$ protein level that resulted in upregulation of $\mathrm{Bax} / \mathrm{Bcl}-2$ ratio. Flow cytometry results further confirmed the ability of LY294002 on reversing RAGE overexpression-related apoptosis inhibition. Collectively, these results suggested that PI3K/AKT activation may be responsible for RAGE-mediated proliferation and apoptosis inhibition in cervical squamous cancer cells. Indeed, RAGE could also exert its oncogenic role through a variety of molecular mechanisms. For example, Lan et $\mathrm{al}^{35}$ find that knockdown of RAGE expression by RAGE-specific siRNA transfection significantly increased cell death through suppressing the PI3K/AKT/mTOR axis. One group has demonstrated that RAGE mediates S100B ability of stimulating colon adenocarcinoma Caco-2 cells proliferation via RAGE/pAKT/mTOR pathway. ${ }^{34}$ In addition, the study of Wu et al ${ }^{40}$ shows HMGB1/RAGE axis is responsible for renal cell carcinoma apoptosis. Luo et $\mathrm{al}^{41}$ reported that miR-328-5p regulates breast cancer proliferation and apoptosis through inhibition of RAGE.

However, there are several limitations existing in our study that need to be discussed. First, we need clinical samples to confirm the results that RAGE is responsible 
for cervical squamous cancer cell proliferation and apoptosis. Second, an in-depth research is needed to study the role of RAGE in cervical squamous cancer bio-behaviors. Taken above, we concluded that overexpression of RAGE promoted proliferation and inhibited apoptosis, conversely, knockdown of RAGE repressed proliferation and induced apoptosis in cervical squamous cancer. Moreover, the specific RAGE inhibitor FPS-ZM1 effectively inhibited proliferation and induced apoptosis in cervical squamous cancer cell. These findings may provide an important mechanism through which RAGE promotes cervical cancer development and provides an alternative target for clinical treatment of cervical squamous cancer. In spite of all these results, the upstream genes or factors of RAGE are still needed to be explored.

\section{Conclusions}

In summary, our data demonstrate that RAGE plays an important role in cervical squamous cancer cells proliferation and apoptosis. Further, the experiments reveal that RAGE promotes the growth ability of cervical squamous cell carcinoma by inducing PCNA expression and inhibiting cell apoptosis via the PI3K/AKT pathway.

\section{Funding}

This research was financially supported through grants from the Wenzhou Science and Technology Projects (Y20170126), Medical Science and Technology Project of Zhejiang Province (2019RC212) and Science and Technology Innovation Team of Wenzhou cityGynecological Oncology (C20170004). Sponsors of the study had no involvement in the collection, analysis, and interpretation of data or the writing of the manuscript.

\section{Disclosure}

The authors declare there are no conflicts of interest in this work.

\section{References}

1. Siegel RL, Miller KD, Jemal A. Cancer statistics, 2019. CA Cancer J Clin. 2019;69(1):7-34. doi:10.3322/caac.v69.1

2. Greten FR, Grivennikov SI. Inflammation and cancer: triggers, mechanisms, and consequences. Immunity. 2019;51(1):27-41. doi:10. 1016/j.immuni.2019.06.025

3. Ritter B, Greten FR. Modulating inflammation for cancer therapy. J Exp Med. 2019;216(6):1234-1243. doi:10.1084/jem.20181739

4. Bouvard V, Baan R, Straif K, et al. A review of human carcinogens-Part B: biological agents. Lancet Oncol. 2009;10 (4):321-322. doi:10.1016/S1470-2045(09)70096-8
5. Neeper M, Schmidt AM, Brett J, et al. Cloning and expression of a cell surface receptor for advanced glycosylation end products of proteins. J Biol Chem. 1992;267(21):14998-15004.

6. Ahagh MH, Dehghan G, Mehdipour M, et al. Synthesis, characterization, anti-proliferative properties and DNA binding of benzochromene derivatives: increased $\mathrm{Bax} / \mathrm{Bcl}-2$ ratio and caspase-dependent apoptosis in colorectal cancer cell line. Bioorg Chem. 2019;93: 103329. doi:10.1016/j.bioorg.2019.103329

7. Schmidt AM, Schmidt AM, Du Yan S, Yan SF, Stern DM. The multiligand receptor RAGE as a progression factor amplifying immune and inflammatory responses. J Clin Invest. 2001;108 (7):949-955. doi:10.1172/JCI200114002

8. Riehl A, Németh J, Angel P, et al. The receptor RAGE: bridging inflammation and cancer. Cell Commun Signal. 2009;7(1):12. doi:10.1186/1478-811X-7-12

9. Sparvero LJ, Asafu-Adjei D, Kang R, et al. RAGE (Receptor for Advanced Glycation Endproducts), RAGE ligands, and their role in cancer and inflammation. $J$ Transl Med. 2009;7(1):17. doi:10.1186/ 1479-5876-7-17

10. Taguchi A, Blood DC, Del Toro G, et al. Blockade of RAGE-amphoterin signalling suppresses tumour growth and metastases. Nature. 2000;405(6784):354-360. doi:10.1038/35012626

11. Kang R, Tang D, Schapiro NE, et al. The receptor for advanced glycation end products (RAGE) sustains autophagy and limits apoptosis, promoting pancreatic tumor cell survival. Cell Death Differ. 2010;17(4):666-676. doi:10.1038/cdd.2009.149

12. Logsdon CD, Fuentes M, Huang E, et al. RAGE and RAGE ligands in cancer. Curr Mol Med. 2007;7(8):777-789. doi:10.2174/15665 2407783220697

13. Kwak T, Drews-Elger K, Ergonul A, et al. Targeting of RAGE-ligand signaling impairs breast cancer cell invasion and metastasis. Oncogene. 2017;36(11):1559-1572. doi:10.1038/onc.2016.324

14. Kalea AZ, See F, Harja E, et al. Alternatively spliced RAGEv1 inhibits tumorigenesis through suppression of JNK signaling. Cancer Res. 2010;70(13):5628-5638. doi:10.1158/0008-5472.CAN-10-0595

15. Hsieh HL, Schäfer BW, Sasaki N, et al. Expression analysis of S100 proteins and RAGE in human tumors using tissue microarrays. Biochem Biophys Res Commun. 2003;307(2):375-381. doi:10.1016/ S0006-291X(03)01190-2

16. Ishiguro H, Nakaigawa N, Miyoshi $\mathrm{Y}$, et al. Receptor for advanced glycation end products (RAGE) and its ligand, amphoterin are overexpressed and associated with prostate cancer development. Prostate. 2005;64(1):92-100. doi:10.1002/(ISSN)1097-0045

17. Kuniyasu H, Chihara Y, Takahashi T. Co-expression of receptor for advanced glycation end products and the ligand amphoterin associates closely with metastasis of colorectal cancer. Oncol Rep. 2003;10 (2):445-448.

18. Kuniyasu H, Oue N, Wakikawa A, et al. Expression of receptors for advanced glycation end-products (RAGE) is closely associated with the invasive and metastatic activity of gastric cancer. $J$ Pathol. 2002;196(2):163-170. doi:10.1002/(ISSN)1096-9896

19. Hudson BI, Kalea AZ, Del Mar Arriero M, et al. Interaction of the RAGE cytoplasmic domain with diaphanous-1 is required for ligand-stimulated cellular migration through activation of Rac1 and Cdc42.J Biol Chem. 2008;283(49):34457-34468. doi:10.1074/jbc.M801465200

20. Yamagishi S, Matsui T, Fukami K. Role of receptor for advanced glycation end products (RAGE) and its ligands in cancer risk. Rejuvenation Res. 2015;18(1):48-56. doi:10.1089/rej.2014.1625

21. Zhu X, Jin L, Zou S, et al. Immunohistochemical expression of RAGE and its ligand (S100A9) in cervical lesions. Cell Biochem Biophys. 2013;66(3):843-850. doi:10.1007/s12013-013-9515-x

22. Healey GD, Pan-Castillo B, Garcia-Parra J, et al. Antibody drug conjugates against the receptor for advanced glycation end products (RAGE), a novel therapeutic target in endometrial cancer. $J$ Immunother Cancer. 2019;7(1):280. doi:10.1186/s40425-019-07 $65-\mathrm{z}$ 
23. Gebhardt C, Riehl A, Durchdewald M, et al. RAGE signaling sustains inflammation and promotes tumor development. J Exp Med. 2008;205(2):275-285. doi:10.1084/jem.20070679

24. Liliensiek B, Weigand MA, Bierhaus A, et al. Receptor for advanced glycation end products (RAGE) regulates sepsis but not the adaptive immune response. J Clin Invest. 2004;113(11):1641-1650. doi:10.11 72/JCI200418704

25. Hiwatashi K, Ueno S, Abeyama K, et al. A novel function of the receptor for advanced glycation end-products (RAGE) in association with tumorigenesis and tumor differentiation of HCC. Ann Surg Oncol. 2008;15(3):923-933. doi:10.1245/s10434-007-9698-8

26. Takada M, Koizumi T, Toyama H, et al. Differential expression of RAGE in human pancreatic carcinoma cells. Hepatogastroenterology. 2001;48(42):1577-1578

27. Kuniyasu H, Chihara Y, Kondo H. Differential effects between amphoterin and advanced glycation end products on colon cancer cells. Int J Cancer. 2003;104(6):722-727. doi:10.1002/(ISSN)10970215

28. Boehm EM, Gildenberg MS, Washington MT. The many roles of PCNA in eukaryotic DNA replication. Enzymes. 2016;39:231-254.

29. Korsmeyer SJ, Shutter JR, Veis DJ, et al. Bcl-2/Bax: a rheostat that regulates an anti-oxidant pathway and cell death. Semin Cancer Biol. 1993;4(6):327-332.

30. Constien R, Forde A, Liliensiek B, et al. Characterization of a novel EGFP reporter mouse to monitor Cre recombination as demonstrated by a Tie2 Cre mouse line. Genesis. 2001;30(1):36-44. doi:10.1002/ gene.v30:1

31. Mizumoto S, Sugahara K. Glycosaminoglycans are functional ligands for receptor for advanced glycation end-products in tumors. FEBS J. 2013;280(10):2462-2470. doi:10.1111/febs.12156

32. Ishibashi Y, Matsui T, Takeuchi M, et al. Metformin inhibits advanced glycation end products (AGEs)-induced growth and VEGF expression in MCF-7 breast cancer cells by suppressing AGEs receptor expression via AMP-activated protein kinase Horm Metab Res. 2013;45(5):387-390. doi:10.1055/s-0032-133 1204
33. Jang EJ, Baek SE, Kim EJ, et al. HMGB1 enhances AGE-mediated VSMC proliferation via an increase in 5-LO-linked RAGE expression. Vascul Pharmacol. 2019;118-119:106559. doi:10.1016/ j.vph.2019.04.001

34. Seguella L, Capuano R, Pesce M, et al. S100B protein stimulates proliferation and angiogenic mediators release through RAGE/pAkt/ mTOR pathway in human colon adenocarcinoma Caco-2 cells. Int J Mol Sci. 2019;20(13):3240. doi:10.3390/ijms20133240

35. Lan CY, Chen S-Y, Kuo C-W, et al. Quercetin facilitates cell death and chemosensitivity through RAGE/PI3K/AKT/mTOR axis in human pancreatic cancer cells. J Food Drug Anal. 2019;27 (4):887-896. doi:10.1016/j.jfda.2019.07.001

36. Liu Q, Huo Y, Zheng H, et al. Ethyl pyruvate suppresses the growth, invasion and migration and induces the apoptosis of nonsmall cell lung cancer cells via the HMGB1/RAGE axis and the NFkappaB/ STAT3 pathway. Oncol Rep. 2019;42(2):817-825. doi:10.3892/ or.2019.7176

37. Fang L, Zhang Y, Wang Q, et al. A polysaccharide from Huaier ameliorates cisplatin nephrotoxicity by decreasing oxidative stress and apoptosis via PI3K/AKT signaling. Int J Biol Macromol. 2019;139:932-943. doi:10.1016/j.ijbiomac.2019.07.219

38. Tian T, Sun J, Wang J, et al. Isoliquiritigenin inhibits cell proliferation and migration through the PI3K/AKT signaling pathway in A549 lung cancer cells. Oncol Lett. 2018;16(5):6133-6139. doi:10.3892/ ol.2018.9344

39. Liao J, Jin H, Li S, et al. Apatinib potentiates irradiation effect via suppressing PI3K/AKT signaling pathway in hepatocellular carcinoma. J Exp Clin Cancer Res. 2019;38(1):454. doi:10.1186/ s13046-019-1419-1

40. Wu CZ, Zheng -J-J, Bai Y-H, et al. HMGB1/RAGE axis mediates the apoptosis, invasion, autophagy, and angiogenesis of the renal cell carcinoma. Onco Targets Ther. 2018;11:4501-4510. doi:10.2147/ OTT

41. Luo T, Yan Y, He Q, et al. miR-328-5p inhibits MDA-MB-231 breast cancer cell proliferation by targeting RAGE. Oncol Rep. 2018;39 (6):2906-2914. doi:10.3892/or.2018.6353
OncoTargets and Therapy

\section{Publish your work in this journal}

OncoTargets and Therapy is an international, peer-reviewed, open access journal focusing on the pathological basis of all cancers, potential targets for therapy and treatment protocols employed to improve the management of cancer patients. The journal also focuses on the impact of management programs and new therapeutic agents and protocols on patient perspectives such as quality of life, adherence and satisfaction. The manuscript management system is completely online and includes a very quick and fair peer-review system, which is all easy to use. Visit http://www.dovepress.com/ testimonials.php to read real quotes from published authors. 